\title{
The role of parasite-driven selection in shaping landscape genomic structure in red grouse (Lagopus lagopus scotica)
}

\author{
November 9, 2015
Marius A. Wenzel*, Alex Douglas, Marianne C. James§, Steve M. Redpath \& Stuart B. Piertney

Institute of Biological and Environmental Sciences, University of Aberdeen, Tillydrone Avenue, Aberdeen AB24 2TZ, UK

* corresponding author. email address: marius.a.wenzel.08@aberdeen.ac.uk. Phone number: +44 1224 272395. Fax number: +44 (0)1224 272396

$\S$ current address: Food Standards Scotland, Aberdeen AB11 5RL, UK

Keywords: landscape genomics, population genomics, $F_{\mathrm{ST}}$ outliers, natural selection, parasites

Running title: Parasite-driven selection in red grouse

\begin{abstract}
Landscape genomics promises to provide novel insights into how neutral and adaptive processes shape genome-wide variation within and among populations. However, there has been little emphasis on examining whether individual-based phenotype-genotype relationships derived from approaches such as genome-wide association (GWAS) manifest themselves as a population-level signature of selection in a landscape context. The two may prove irreconcilable as individual-level patterns may become diluted by high levels of gene flow and complex phenotypic or environmental heterogeneity. We illustrate this issue with a case study that examines the role of the highly prevalent gastrointestinal nematode Trichostrongylus tenuis in shaping genomic signatures of selection in red grouse (Lagopus lagopus scotica). Individual-level GWAS involving 384 SNPs has previously identified five SNPs that explain variation in T. tenuis burden. Here, we examine whether these same SNPs display population-level relationships between T. tenuis burden and genetic structure across a small-scale landscape of 21 sites with heterogeneous parasite pressure.
\end{abstract}

This article has been accepted for publication and undergone full peer review but has not been through the copyediting, typesetting, pagination and proofreading process, which may lead to differences between this version and the Version of Record. Please cite this article as doi:

This article is protected by copyright. All rights reserved. 


\begin{abstract}
Moreover, we identify adaptive SNPs showing signatures of directional selection using $F_{\mathrm{ST}}$ outlier analysis and relate population- and individual-level patterns of multi-locus neutral and adaptive genetic structure to T. tenuis burden. The five candidate SNPs for parasite-driven selection were neither associated with $T$. tenuis burden on a population level, nor under directional selection. Similarly, there was no evidence of parasite-driven selection in SNPs identified as $F_{\mathrm{ST}}$ outliers. We discuss these results in the context of red grouse ecology and highlight the broader consequences for the utility of landscape genomics approaches for identifying signatures of selection.
\end{abstract}

\title{
Introduction
}

A central focus in molecular ecology is to understand how different demographic and environmental drivers impact upon the stochastic and deterministic micro-evolutionary forces that define the levels of standing genetic variation and affect individual fitness and population dynamics (Kirk \& Freeland 2011; Andrew et al. 2013; Ellegren 2014). The classic field of landscape genetics examines patterns of neutral genetic diversity in a spatially explicit context and aims to identify barriers to gene flow that affect stochastic micro-evolutionary processes (Manel et al. 2003; Storfer et al. 2007). The more nascent field of landscape genomics extends such ideas towards linking the spatial distribution of adaptive genetic diversity to microgeographic heterogeneity in environmental factors that underpin natural selection and local adaptation (Joost et al. 2007; Manel et al. 2010). Identifying such links promises to elucidate the causes and consequences of adaptive evolution in natural populations (Parisod \& Holderegger 2012; Joost et al. 2013; Rellstab et al. 2015).

The principal challenges in landscape genomics are, firstly, to detect the signatures of selection operating against a neutral genome-wide background and, secondly, to identify the environmental factors that underpin selection (Schoville et al. 2012; Rellstab et al. 2015). Two principal strategies for identifying target polymorphisms can be distinguished. The traditional approach takes an exploratory route that moves "from population to individual", whereby candidate molecular markers showing population-level signatures of selection are identified from disproportionate global genetic differentiation compared to the genomic average $\left(F_{\mathrm{ST}}\right.$ outliers) (Lewontin \& Krakauer 1973; Beaumont \& Nichols 1996; Storz 2005). Geographic patterns of spatial genetic structure among individuals or populations are then compared between the candidate adaptive and neutral components of genome-wide information and statistically related to environmental factors suspected to exert selection pressure (Joost et al. 2007; Manel et al. 2010). Alternatively, however, the application of phenotype-genotype mapping in natural population, using methods such as QTL mapping or genome-wide association (GWAS) (Slate 2005; Schielzeth \& Husby

This article is protected by copyright. All rights reserved. 
2014), has led to a growing emphasis on the opposite strategy of moving "from individual to population". This involves identifying candidate adaptive genetic markers underpinning ecologically important phenotypes using individual-based gene-mapping methods, and then examining associations between genetic variation in these markers and environmental variables in a spatially explicit population genomics context (Johnston et al. 2014). The rationale underlying this strategy is that selection defining the identified candidate genetic variants among individuals should drive population genomic divergence across a landscape with environmental heterogeneity.

The traditional "from population to individual" strategy has been used effectively in terrestrial and aquatic systems to study selection associated with geological and climatic variables (e.g., Manel et al. 2009; Pariset et al. 2009; Richter-Boix et al. 2011; Hess et al. 2013; Vincent et al. 2013), aquatic habitat factors such as temperature and salinity (e.g., Nielsen et al. 2009; Shikano et al. 2010; Matala et al. 2011; Limborg et al. 2012; Pespeni \& Palumbi 2013; Milano et al. 2014), and biotic factors such as predators, (e.g., RichterBoix et al. 2011; Orsini et al. 2012, 2013) parasites (e.g., Orsini et al. 2012, 2013; Zueva et al. 2014) or behavioural life-history phenotypes (e.g., Hess et al. 2013). Generally, such studies identify environmental drivers of selection by seeking congruence across the candidate adaptive markers generated by $F_{\mathrm{ST}}$ outlier tests and individual-based linear modelling or population-based association methods. The "from individual to population" strategy has been used predominantly to study selection on complex migratory phenotypes in trout and salmon species, where candidate markers were first identified through individual-based modelling and then tested using population-based $F_{\text {ST }}$ outlier and association tests (Narum et al. 2011; Hess \& Narum 2011; Narum et al. 2013; Johnston et al. 2014; Matala et al. 2014).

Congruence across both these strategies provides the strongest evidence of selection shaping the patterns of genetic diversity across populations (Johnston et al. 2014; Matala et al. 2014). However, such congruence may be problematic to obtain in small-scale landscape systems, especially when focal populations show weak population structure through ongoing gene flow or large effective population sizes, or ore characterised by complex phenotypic or environmental heterogeneity (Rellstab et al. 2015). In these cases, population-level patterns may be affected by dispersal to a greater extent than selection and, in consequence, may be a poor reflection of fine-scale adaptive processes among individuals. For example, $F_{\mathrm{ST}}$ outlier tests often provide inconsistent and misleading results in landscape systems, because the implemented population models may be inappropriate for capturing fine-scale variation in gene flow across complex landscapes (Narum \& Hess 2011; Lotterhos \& Whitlock 2014, 2015). Similarly, the expectation to find strong signatures of population differentiation at individual loci may be unrealistic if selection acts on complex, potentially polygenic phenotypes underpinned by a large number of loci with individually small effects (Pritchard \& Di Rienzo 2010; Bourret et al. 2014). These

This article is protected by copyright. All rights reserved. 
issues can cause failure to identify signatures of selection in a "from population to individual" analysis, and may thus hamper reconciling individual-level selective processes with population-level patterns to arrive at a consistent picture of the effects of selection on genetic diversity in natural populations.

Here we illustrate how individual-based genotype-phenotype relationships can be lost in a small-scale landscape system of red grouse (Lagopus lagopus scotica), with particular focus on parasite-driven selection. Red grouse are a subspecies of the willow ptarmigan and are endemic to the upland heather moors of Scotland and northern England (Martínez-Padilla et al. 2014c). Both males and females display relatively low levels of dispersal, rarely travelling more than $5 \mathrm{~km}$ from their natal site (Jenkins et al. 1963). Moreover, male grouse are highly territorial and establish territories close to their kin, resulting in spatial family structures within populations (Watson et al. 1994; MacColl et al. 2000; Piertney et al. 1999, 2008). Combined, these processes underpin high levels of localised genetic structure. Both microsatellite and mitochondrial DNA polymorphisms show significant genetic divergence over the scale of a few kilometres (Piertney et al. 1998, 2000), with an overall signature of isolation by distance that can be interrupted by barriers to gene flow such as rivers (Piertney et al. 1998). In contrast, adaptive genetic diversity based on an MHC locus is structured much more weakly than neutral genetic diversity in the same landscape (Piertney 2003), illustrating the potential for natural selection to influence the spatio-temporal distribution of adaptive genetic variation.

A particularly important environmental factor expected to drive potent selection in red grouse is chronic infection by the highly prevalent gastrointestinal nematode Trichostrongylus tenuis (Martínez-Padilla et al. 2014c). This parasite exhibits a direct life cycle with larvae being ingested by grouse while feeding on heather shoots, adults establishing in the gut caeca and eggs being shed with faeces (Hudson et al. 1992b; Saunders et al. 1999). Adult worms burrow into the caecal walls where they cause haemorrhaging and necrosis with substantial downstream consequences for energy balance, fecundity and survival (Hudson 1986; Watson et al. 1987; Hudson et al. 1992a; Delahay et al. 1995; Delahay \& Moss 1996). Prevalence of T. tenuis infection among grouse is typically greater than $90 \%$ and individuals bear chronic parasite burdens due to an inability to purge the infection (Wilson 1983; Shaw \& Moss 1989; Webster et al. 2011a). Chronic exposure to T. tenuis insult has marked effects on grouse life history and population dynamics, mediated through trade-offs with testosterone-mediated sexual selection processes (Martínez-Padilla et al. 2007, 2010; Mougeot et al. 2007, 2009, 2010a,b; Vergara et al. 2012b; Wenzel et al. 2013), recruitment behaviour (Watson 1985; Watson et al. 1994; Fox \& Hudson 2001; Mougeot et al. 2005a,b) and immunocompetence (Lochmiller 1996; Hudson et al. 1998; Mougeot et al. 2005a; Redpath et al. 2006; Webster et al. 2011b).

Given these important fitness effects, several studies have attempted to identify the genetic basis of the physiological response to T. tenuis infection and variation in chronic

This article is protected by copyright. All rights reserved. 
T. tenuis burden. Analysis of differential gene expression identified key genes upregulated in birds with elevated parasite burden (Webster et al. 2011a,b), and genotypic variation at several candidate genes and $\mathrm{CpG}$ epiloci explains significant amounts of variance in parasite burden among individuals (Wenzel \& Piertney 2014, 2015). Most recently, GWAS involving 384 SNP loci has identified five SNPs with predominantly additive allelic effects on $T$. tenuis burden in a large sample of red grouse from five locations (Wenzel et al. 2015). However, what remains to be established is how genetic diversity at these SNPs is apportioned across a landscape with heterogeneous parasite pressure, and whether this spatial distribution is consistent with expectations from parasite-driven directional selection. The key predictions are that allele frequencies would vary as a consequence of prevailing parasite burden and that populations with contrasting parasite burdens would be disproportionately differentiated at these loci.

In the present study, we examine spatial genome-wide neutral and adaptive genetic structure across a landscape of red grouse and test whether any observed genetic structure is associated with parasite burden, using the same set of 384 unlinked genome-wide SNPs that includes five candidate SNPs for parasite-driven directional selection based on individual-level GWAS (Wenzel et al. 2015). We use a "from individual to population" strategy and test whether allele frequencies of these five candidate SNPs are associated with parasite burden and show signatures of directional natural selection on a population level. In parallel, we take a "from population to individual" route that identifies candidate neutral and adaptive marker sets from $F_{\mathrm{ST}}$ outlier tests and examines whether the adaptive component of genetic structure among populations and individuals is associated with parasite burden. Our study system is the same landscape system where neutral markers have identified considerable genetic structure (Piertney et al. 1998), and variation in candidate genes and epiloci is known to explain variation in T. tenuis burden (Wenzel \& Piertney 2014, 2015). We hypothesise that allele frequencies of the five candidate SNPs known to be associated with nematode burden in individual-based analysis (Wenzel et al. 2015) are associated with parasite burden on a population level and exhibit disproportionate genetic structure in line with candidate adaptive markers identified in $F_{\text {ST }}$ outlier tests. We further hypothesise that markers identified as effectively neutral by a "from population to individual" analysis will follow a geographical isolation-by-distance relationship, consistent with previous work on microsatellites (Piertney et al. 1998).

\section{Materials \& Methods}

\section{Sampling and genotyping}

A total of 231 shot grouse were sampled following driven or walked-up sporting shoots across 21 sites near Deeside in autumn 2012 (Fig. 1; Table 1). These sites represent the

This article is protected by copyright. All rights reserved. 
core distribution of red grouse in north-east Scotland (Piertney et al. 1998, 2000; Wenzel \& Piertney 2014, 2015). The geographic distances among these sites ranged from c. 1.8 to $58.9 \mathrm{~km}$ (median $=26.2 \mathrm{~km}$ ), and typical dispersal distances among these populations of less than $5 \mathrm{~km}$ ensure that this sampling scale provides an appropriate resolution for landscape genetics studies (Jenkins et al. 1963; Piertney et al. 1998, 2000; Piertney 2003). Estate management practice at fifteen of these 21 sites had involved nematode control by scattering quartz grit covered in anthelmintic medication across the moors for at least two years immediately prior to sampling. Grouse ingest this grit during feeding to aid digestion, which effectively reduces $T$. tenuis burdens in medicated populations without evidence of drug resistance (Newborn \& Foster 2002; Webster et al. 2008; Cox et al. 2010). Six of the 21 sites had been medication-free for at least ten years, causing heterogeneity in parasite pressure across this landscape (Fig. 1; Table 1).

Individuals were aged ("young": hatched in 2012; "old": > 1 year) based on body size and plumage, and old birds were preferentially sampled to minimise sampling bias through over-representation of kin groups (Piertney et al. 2008). T. tenuis burdens were estimated from gut caeca via faecal egg counts, using the standard McMaster chamber counting slide method and prediction functions (Seivwright et al. 2004). Physiological condition was ascertained by measuring body mass to the nearest $10 \mathrm{~g}$ and calculating supra-orbital comb area to the nearest $\mathrm{mm}^{2}$. Comb area in both male and female red grouse is a sexual signal and a good proxy for physiological condition (Mougeot et al. 2004, 2005c, 2009; Martínez-Padilla et al. 2010; Martinez-Padilla et al. 2011; Vergara et al. 2012a,b; Wenzel \& Piertney 2014, 2015).

DNA was extracted from 2-3 c. $2 \mathrm{~mm}^{3}$ shreds of liver tissue following Hogan et al. (2008). Each bird was sexed genetically based on CHD polymorphism (Griffiths et al. 1998) as described in Wenzel et al. (2012). All individuals were genotyped at 384 redgrouse specific SNPs covering almost the entire chicken genome (Wenzel et al. 2015). Genotype data were quality filtered as described in Wenzel et al. (2015).

\section{Statistical methods}

The overall analysis comprised three components: First, in order to test whether the five candidate SNPs previously identified from individual-level GWAS (Wenzel et al. 2015) are associated with $T$. tenuis burden in a spatially explicit population genomics context, SNP-by-SNP landscape genomics analyses were carried out. Second, genome scans for $F_{\text {ST }}$ outliers were used to identify population-level signatures of natural selection in individual SNPs, and to divide the 384 SNPs into putatively adaptive and neutral multi-locus datasets (e.g., Limborg et al. 2012; Matala et al. 2014; Moore et al. 2014; Milano et al. 2014). Third, geographic patterns of adaptive spatial genetic structure among populations and individuals were examined and related to T. tenuis burden.

This article is protected by copyright. All rights reserved. 
For the purpose of population-based statistical approaches, each sampling site was assumed to be a separate "population" to ensure consistency with previous landscape genetics studies in this system (Piertney et al. 1998, 2000; Piertney 2003). Differences in anthelmintic medication regimen across the populations were included into analyses to account for the confounding effect on T. tenuis burden (Newborn \& Foster 2002).

\section{Individual-to-population landscape genomics}

Hierarchical AMOVA analyses were carried out in ARLEQUIN 3.5 (Excoffier \& Lischer 2010) to test whether groups of populations with similar median parasite burdens or identical medication regimen are significantly genetically differentiated at individual SNPs (Excoffier et al. 1992). The populations were divided into five groups according to $T$. tenuis burden or two groups according to the presence or absence of anthelmintic medication (Fig. 1). T. tenuis burdens were binned using logarithmic $k$-means clustering with manual modification to moderate sample size differences. Total genetic variance was decomposed into variance among groups of populations $\left(F_{\mathrm{CT}}\right)$, among populations within groups $\left(F_{\mathrm{SC}}\right)$ and within populations $\left(F_{\mathrm{ST}}\right)$, and statistical significance was estimated from 10,000 permutations.

To directly examine the role of geography, medication regime and parasite burden in shaping genetic differentiation among populations, isolation-by-distance and isolation-bystressor tests were carried out. Linearized pairwise genetic differentiation $\left(G_{\mathrm{ST}}\right)$ estimates were obtained from the package diveRsity (Keenan et al. 2013) in R 3.0.3 (R Core Team 2014). Associations of genetic distance with differences in longitude, latitude or logarithmic geographic distances were examined using Mantel tests with 9,999 permutations as implemented in the $\mathrm{R}$ package ecodist (Goslee \& Urban 2007). Associations of genetic distance with differences in logarithmic median T. tenuis burden were examined using partial Mantel tests (Smouse et al. 1986), conditioning for differences in anthelmintic medication regimen and logarithmic geographic distance.

These same associations were also tested using distance-based canonical redundancy analysis (dbRDA) of pairwise genetic differentiation, implemented in the R package vegan (Oksanen et al. 2013). This method is a form of multivariate linear regression that allows for estimating the proportion of variance in a distance matrix that can be reconstructed by constrained ordination of multiple explanatory variables (Legendre \& Fortin 2010). The distance matrix contained linearized pairwise $G_{\mathrm{ST}}$ estimates, and the fitted model contained either longitude and latitude, or logarithmic median T. tenuis burden conditioned by anthelmintic medication regimen, longitude and latitude. Adjusted $R^{2}$ of the model was obtained and statistical significance of the canonical axes was estimated using the marginal test method and 9,999 permutations (Legendre et al. 2011).

In all three analyses, single-test significance estimates were corrected for multiple testing using the Benjamini-Hochberg approach to controlling the false discovery rate

This article is protected by copyright. All rights reserved. 
(Benjamini \& Hochberg 1995). The effect sizes and significance estimates for the five candidate SNPs (Wenzel et al. 2015) were singled out and compared to those of the remaining SNPs.

\section{Population-level signatures of natural selection}

Three types of $F_{\text {ST }}$ outlier tests were carried out to identify candidate SNPs for directional selection from disproportionately large global differentiation among the 21 populations. First, the FDIST method was used to identify SNPs with $F_{\mathrm{ST}}$ outside the liberal upper tail of the empirical neutral distribution $(P>0.95)$ based on an island population model, using LOSITAN (Antao et al. 2008) with $3 \cdot 10^{5}$ simulations, "neutral $F_{\text {ST" }}$ and "force mean $F_{\text {ST }}$ " options and default sampling parameters. Second, a hierarchical island model method was used to tease apart SNP-specific contributions from genome-wide contributions to population differentiation, using BAYESCAN2 (Foll \& Gaggiotti 2008) with a significance threshold of $q \leq 0.05$ after $2 \cdot 10^{6}$ iterations (run length $10^{5}$; thinning interval 20 ) following 20 pilot runs $\left(10^{4}\right.$ iterations each) and a burn-in of $5 \cdot 10^{5}$. Third, SNPs were empirically ranked by their degree of contribution to population differentiation, correcting for among-population correlation of allele frequencies, using BAYENV2 (Coop et al. 2010; Günther \& Coop 2013). A pilot analysis estimated the among-population correlation matrix from all 384 SNPs together in a single run with $10^{7}$ iterations, followed by independent runs (all $10^{7}$ iterations) for each SNPs to estimate the $X^{T} X$ differentiation statistic from standardised allele frequencies accounting for the population correlation matrix. An empirical neutral correlation matrix was then estimated after removing the five GWAS SNPs and all SNPs with $X^{T} X$ larger than the 95th percentile of the empirical distribution. The final $X^{T} X$ estimates for each of all 384 SNPs were obtained in a second run accounting for the neutral correlation matrix, and SNPs with $X^{T} X>95$ th percentile were considered outliers.

These three tests implement different population models and, as such, vary in power and specificity, particularly for small-scale landscape systems (De Mita et al. 2013; Lotterhos \& Whitlock 2014, 2015). Therefore, the five GWAS SNPs were considered outliers if they exceeded the liberal thresholds for directional selection or analogous thresholds $\left(P<0.05\right.$ or $X^{T} X<5$ th percentile) for balancing selection in any of the three tests. To further identify robust candidates for directional selection for defining an adaptive multilocus dataset, we only considered SNPs that were identified by at least two outlier tests. A conservative neutral multi-locus dataset was generated by removing all SNPs that were identified as outliers in any of the three tests.

This article is protected by copyright. All rights reserved. 


\section{Population-level landscape genomics}

The genetic distinctiveness of each of the 21 populations was quantified by estimating population-specific local $F_{\mathrm{ST}}$ (Gaggiotti \& Foll 2010) from the defined neutral and adaptive multi-locus datasets independently, using a Bayesian approach implemented in GESTE (Foll \& Gaggiotti 2006) with $2 \cdot 10^{6}$ iterations (run length $10^{5}$; thinning interval 20) following 20 pilot runs $\left(10^{4}\right.$ iterations each) and a burn-in of $5 \cdot 10^{5}$. These estimates were simultaneously regressed on standardized longitude, latitude, median T. tenuis burden and medication regimen variables individually and in all possible combinations. The posterior likelihoods of all fitted linear models were then used to identify those predictor combinations that best explain the observed genetic structure (Foll \& Gaggiotti 2006). For comparison, hierarchical AMOVA, Mantel tests and dbRDA were carried out based on pairwise genetic differentiation $\left(G_{\mathrm{ST}}\right)$ among populations in the same fashion as described earlier for the individual-to-population analysis. Hierarchical AMOVA was also used to test whether populations north and south of the river Dee (Fig. 1) are significantly differentiated, as expected from microsatellite data (Piertney et al. 1998).

\section{Population-to-individual landscape genomics}

This final analysis component aimed to examine associations of individual-level genetic structure with $T$. tenuis burden, based on the defined multi-locus neutral and adaptive datasets. Individual-based neutral and adaptive genetic structure was inferred using the Bayesian population model implemented in STRUCTURE 2.3.4 (Pritchard et al. 2000; Falush et al. 2003) and model-free discriminant analysis of principal components (DAPC; Jombart et al. 2010) implemented in the $\mathrm{R}$ package adegenet (Jombart 2008; Jombart \& Ahmed 2011). STRUCTURE assigns each individual a membership probability for each of a specified number of ancestral genetic clusters, such that each cluster conforms to Hardy-Weinberg and linkage equilibrium (Pritchard et al. 2000; Falush et al. 2003). DAPC identifies linear discriminant functions on multidimensional genotype space (represented by principal components) that maximise genetic variation between specified or inferred clusters and minimise variation within these clusters (Jombart et al. 2010). These genetic structure metrics were then fitted as a predictor of $T$. tenuis burden in generalized linear models that account for environmental and phenotypic covariates (Bashalkhanov et al. 2013).

STRUCTURE analysis was carried out to infer $K=1$ to $K=21$ genetic clusters using the standard admixture model with correlated allele frequencies, $10^{6}$ iterations burn-in, $10^{6} \mathrm{MCMC}$ iterations and ten replicates for each $K$. To improve the power to detect genetic structure, the analysis was repeated using sampling location of each individual as a prior parameter (locprior option; Hubisz et al. 2009). Results were compiled and analysed using STRUCTURE HARVESTER (Earl \& vonHoldt 2012) and the most likely number of

This article is protected by copyright. All rights reserved. 
genetic clusters was ascertained by posterior likelihood and $\Delta \mathrm{K}$ statistics (Evanno et al. 2005). Replicate runs for each $K$ were averaged in CLuMPP (Jakobsson \& Rosenberg 2007) using the Greedy algorithm and 100 random input sequences. DAPC analysis was carried out using successive $k$-means clustering and BIC model selection to infer the most likely number of clusters to describe the total genetic variation. All principal components were retained for cluster inference. For comparison, the analysis was repeated assigning individuals to their 21 actual sampling populations instead of inferring genetic clusters. Discriminant functions were obtained from all seven principal components (outlier SNPs dataset), or the first 75 principal components (neutral SNPs dataset) to avoid overfitting when the number of principal components exceeds a third of the number of observations $(n=231)$ (Jombart et al. 2010).

Individual T. tenuis burden was modelled as a consequence of genetic, environmental and phenotypic factors (Wenzel \& Piertney 2015), using generalised estimating equations (GEEs) with Poisson error structure as implemented in the geepack package (Halekoh et al. 2006). Cluster membership probability (STRUCTURE) or each of the first two discriminant functions (DAPC) was fitted as the main predictor, alongside medication regimen and supra-orbital comb area as environmental and phenotypic covariates expected to impact nematode burden (Wenzel \& Piertney 2015). Comb area was chosen as a phenotypic proxy variable for sex, age and body mass to avoid complex models that are liable to overfitting and to reflect the established biological and statistical relationships between these phenotypic variables and nematode burden (Wenzel \& Piertney 2014, 2015). To account for correlation of nematode burdens at the same sampling site due to epidemiological neighbourhood effects, the GEEs were fitted with an exchangeable correlation structure within populations (Hubbard et al. 2010; Wenzel \& Piertney 2014, 2015). Additionally, for comparison with classic covariate-free genotype-environment association (Joost et al. 2008), cluster membership probability or discriminant function was regressed on nematode burden by simple linear (DAPC) or beta (STRUCTURE) regression using the betareg package (Cribari-Neto \& Zeileis 2010).

\section{Results}

Estimated T. tenuis burden among the 231 red grouse individuals ranged from 4 to 9,283 (median: 397) worms and population medians ranged from 4 to 2,222 worms (Table 1; Wenzel \& Piertney 2014). Individuals from sites with medicated grit carried considerably lower burdens than those from medication-free sites (medians: 126 and 1,058 worms; Wilcoxon's $W=8327, P<0.001)$. Of the 384 SNPs, 274 passed quality control using the same criteria as in Wenzel et al. (2015) and the distributions of SNP heterozygosities and sample inbreeding coefficients were consistent with Wenzel et al. (2015).

This article is protected by copyright. All rights reserved. 


\section{"From individual to population" strategy}

No evidence was found of associations between T. tenuis burden and allele frequencies of the five candidate SNPs previously identified from GWAS (Wenzel et al. 2015). These SNPs were not differentiated among populations grouped by median nematode burden $\left(F_{C T}=-0.013--0.001, P=0.45-0.76\right)$ or by medication regimen (Fig. 2). Grouping populations by broader nematode burden categories (e.g., as in Wenzel \& Piertney 2014) had no effect on these conclusions. Similarly, although pairwise genetic differentiation among populations did not follow an isolation-by-distance pattern in these SNPs (Mantel $r=-0.02-0.05, P=0.57-0.97$; RA $R^{2}=-0.05-0.12, P=$ $0.07-0.75)$, genetic structure was not explained by differences in median nematode burden, even when accounting for differences in medication regimen and geographic distance $\left(r=-0.04-0.02, P=0.71-0.90 ; R^{2}=-0.03--0.06, P=0.57-0.96\right)$. The one exception was a significant association in SNP X2277 using distance-based RDA $\left(R^{2}=0.20, P=0.01\right.$ ) (Fig. 3), but this SNP had the weakest support out of the five SNPs using GWAS (Wenzel et al. 2015). In spite of some collinearity between median nematode burdens and latitude $\left(F_{1,19}=23.99 ; P<0.001\right)$, the conclusions from all analyses remained unaffected when longitude or latitude were substituted for geographic distance (not shown).

\section{"From population to individual" strategy}

\section{Signatures of natural selection}

Genome scans for $F_{\text {ST }}$ outliers highlighted 23 SNPs with disproportionately large global genetic differentiation among the 21 sampling sites when applying liberal significance thresholds (Fig. 4). LOSITAN and BAYENv2 indicated 16 SNPs $(P>0.95)$ and 14 SNPs $\left(X^{T} X>19\right)$ respectively, and seven of these were congruent across these two methods. One of these seven SNPs was also strongly supported in BAYESCAN2. These seven SNPs are located on six different chicken chromosomes and thus probably represent multiple independent genomic regions. If analogous liberal thresholds were applied to identify balancing selection $\left(P<0.05\right.$ or $\left.X^{T} X<12\right), 20$ SNPs would be highlighted, twelve of which would satisfy both thresholds (Fig. 4). None of these hypothetical candidates for balancing selection were significantly associated with nematode burden in any SNP-bySNP landscape genomic analysis (not shown).

None of the five candidate SNPs previously identified from GWAS (Wenzel et al. 2015) exceeded liberal or stricter thresholds for directional or balancing selection in any of these methods (LOSITAN: $P=0.14-0.94$; BAYENV2: $X^{T} X=13.41-18.64$; BAYESCAN2: $q=0.88-0.90)$. For subsequent landscape genomics analyses, the "adaptive" dataset comprised the seven robust outlier SNPs, and the "neutral" dataset consisted of 251 SNPs

This article is protected by copyright. All rights reserved. 
after removing all 23 suggestive outliers.

\section{Population-level landscape genomics}

Mean population-specific local $F_{\mathrm{ST}}$ ranged from 0.001 to 0.013 for the neutral dataset and 0.024 to 0.154 for the adaptive dataset. Spatial arrangement of population structure using heat colour profiles illustrated that neutral structure was strongest in the south and the east of the landscape with very weak structure in the north, whereas adaptive structure was most prominent in the north (Fig. 5). Similarly, pairwise $G_{\mathrm{ST}}$ ranged from -0.006 to 0.011 for the neutral dataset and -0.020 to 0.146 for the adaptive dataset, and genetic structure was congruent with patterns in local $F_{\mathrm{ST}}$ (Fig. S1). Common between neutral and adaptive structure, populations 13, 20 and 21 in the east were the most strongly differentiated populations with respect to all others. These three populations caused a correlation between neutral and adaptive local $F_{\text {ST }}$ estimates $\left(r=0.669, t_{19}=3.925, P<\right.$ $0.001)$ as well as pairwise $G_{\mathrm{ST}}$ estimates $\left(r=0.273, t_{208}=4.097, P<0.001\right)$. When these populations were removed, the correlations were not significant $\left(r=-0.170, t_{16}=\right.$ $-0.689, P<0.500$ and $\left.r=0.073, t_{151}=0.895, P=0.372\right)$.

Landscape genomics analyses confirmed a consistent contrast between the geographic distribution of neutral and adaptive genetic variation. Neutral genetic structure as quantified by population-specific local $F_{\mathrm{ST}}$ and pairwise $G_{\mathrm{ST}}$ was associated with geographic distance, primarily longitude, but neither was the case for adaptive genetic structure (Table 2, 3). Distance-based redundancy analysis additionally highlighted a weak latitudinal effect in neutral, but not adaptive, genetic structure (Table 3). This was consistent with hierarchical AMOVA indicating small but significant genetic differentiation among populations north and south of the river Dee in neutral SNPs $\left(F_{\mathrm{CT}}=0.001 ; P=0.009\right)$ but not in outlier $\operatorname{SNPs}_{\mathrm{S}}\left(F_{\mathrm{CT}}=-0.003 ; P=0.590\right)$.

Despite this contrast in the geographic structure of neutral and adaptive genetic variation, there was no evidence that adaptive genetic patterns were associated with T. tenuis burden. Populations grouped by median nematode burden were not significantly differentiated $\left(F_{\mathrm{CT}}=0.001 ; P=0.374\right)$, and neither were populations grouped by anthelmintic medication regimen $\left(F_{\mathrm{CT}}=0.006 ; P=0.178\right)$. Moreover, nematode burden was not a likely predictor of local $F_{\mathrm{ST}}$ either individually or in combination with other predictors (Table 2). Finally, neither Mantel tests nor dbRDA highlighted significant associations of genetic structure with nematode burden (Table 3).

\section{Individual-level landscape genomics}

STRUCTURE failed to infer meaningful neutral genetic structure. Evanno's $\Delta \mathrm{K}$ suggested $K=2$ as the most likely number of clusters, though multiple secondary peaks at $\mathrm{K}$ values as high as 12 and 19 were apparent, with high variance of posterior likelihood

This article is protected by copyright. All rights reserved. 
among replicate runs for $K>2$ (Fig. S2). The membership coefficients for $K=2$ did not assign individuals or populations to distinct groups, and higher $K$ values showed no improvement (Fig. S2). When sampling location was included as prior information, the most likely number of clusters was $K=8$, but there were still no genetic groups (Fig. S2). Similarly, DAPC suggested $K=1$ as the most likely outcome, though forcing $K=2$ or $K=21$ onto the algorithm generated distinct clusters with almost no admixture (Fig. S3).

In contrast, both STRUCTURE and DAPC inferred strong adaptive genetic structure. Evanno's $\Delta \mathrm{K}$ peaked at $K=2$, irrespective of whether sampling location information was included or not. The locprior model additionally suggested $K=3, K=8$ and $K=16$ as secondary peaks, but these additional clusters did not meaningfully alter the structure apparent at $K=2$ (Fig. S2). The two distinct clusters did not coincide with a priori population designations (Fig. S2). Similarly, although DAPC gave no clear indication of the most likely $K$, forcing $K=2$ or $K=21$ produced strong clustering unrelated to $a$ priori populations (Fig. S3).

Notwithstanding, adaptive genetic structure was not associated with T. tenuis burden, irrespective of whether simple regression or more complex models accounting for environmental and phenotypic covariates were used (Table 4). Instead, some simple regression models suggested that neutral genetic structure inferred by DAPC assuming 21 actual or inferred clusters may be linked to nematode burden. However, this was not the case when two genetic clusters were assumed or when accounting for environmental and phenotypic covariance in GEE models (Table 4).

\section{Discussion}

The principal finding of this study is a consistent absence of signatures of selection by chronic T. tenuis infection in landscape genomic structure of red grouse individuals and populations. Crucially, five candidate SNPs for directional parasite-driven selection, which were previously identified through individual-level GWAS (Wenzel et al. 2015), were neither identified as $F_{\mathrm{ST}}$ outliers nor associated with $T$. tenuis burden across the landscape. Similarly, although there were robust signatures of directional natural selection at multiple genomic regions and marked differences in geographic patterns of neutral and adaptive genetic structure, there was no evidence that these signatures were associated with T. tenuis burden. Together, these results highlight irreconcilable patterns between individual-level and population-level methods and suggest that there is no detectable signal of parasitedriven selection on genetic structure across this landscape. Such a lack of parasite-driven effects is difficult to explain given the considerable impact that T. tenuis has on grouse fitness, behaviour and demography (Fox \& Hudson 2001; Martínez-Padilla et al. 2007, 2010; Mougeot et al. 2005a,b, 2007, 2009, 2010a,b; Vergara et al. 2012b), and the substantial

This article is protected by copyright. All rights reserved. 
evidence for transcriptomic (Webster et al. 2011a,b; Wenzel et al. 2013), genomic (Wenzel \& Piertney 2015; Wenzel et al. 2015) and epigenomic (Wenzel \& Piertney 2014) relationships with acute and chronic T. tenuis infection. This discrepancy between individualand population-level patterns tells a cautionary tale of inherent conceptual and biological problems with population-level landscape genomics approaches for detecting signatures of natural selection.

There are several reasons why population-level landscape genomics patterns may be problematic. First, genotypic signatures of selection among individuals may become swamped at the population level by gene flow (Slatkin 1987; Lenormand 2002). Selection of genetic variants initially drives local adaptive divergence among individuals that is detectable by individual-based modelling such as GWAS. However, if the rate and scale of gene flow is such that genetic variants are mixed rapidly across a landscape, selection may not be a detectable driver of population allele frequencies. In red grouse, female-mediated gene flow is known to counteract the genetic structuring promoted by male philopatry and territoriality (Jenkins et al. 1963; Piertney et al. 1998, 2000), and may thus cause sufficient mixing over short time spans to dilute signatures of parasite-driven selection at the population level. This effect is echoed for salinity-driven selection in three-spined sticklebacks, where population-level analysis detected substantially fewer loci under selection in a small-scale landscape of interconnected streams with high gene flow compared to large-scale systems with weak connectivity (Konijnendijk et al. 2015).

Second, the relationship between population genetic structure and environmental variability can be decoupled by delayed genetic responses to temporally fluctuating selection. Spatial coincidence of genetic and environmental information at the time of sampling is assumed to reflect selection (Manel et al. 2010; Joost et al. 2007, 2013), but such relationships may not be detectable if contemporary genetic variation reflects historic selection in a different environment rather than current selection at the sampling site. This mismatch can be exacerbated by highly dynamic environmental factors such as parasite abundance compared to potentially less dynamic abiotic factors such as temperature or humidity (Poulin 2007). This issue was recently highlighted in a study on genomic signatures of predation, parasite and land-use stressors in the waterflea Daphnia magna, by comparing contemporary patterns of stressor-driven selection with historic data obtained from sediment cores (Orsini et al. 2012). In red grouse, absolute T. tenuis abundance fluctuates seasonally and annually, but relative differences in T. tenuis burden among individuals remain similar across years, ensuring consistent adaptive differences among individuals (Moss et al. 1993). Together with evidence of individual-level genomic signatures of contemporary T. tenuis burden in candidate genes (Wenzel \& Piertney 2015) and genome-wide SNPs (Wenzel et al. 2015), this suggest that time lags may be a minor problem.

Third, a further factor that can decouple the relationship between population genetic

This article is protected by copyright. All rights reserved. 
structure and environmental variation is a buffer effect of phenotypic plasticity mediated through epigenetic regulation of gene expression and physiology following dispersal across an environmentally heterogeneous landscape (Bossdorf et al. 2008; Duncan et al. 2014). This effect is particularly apparent in biological invasions or species undergoing range expansions, where epigenetic variation confers rapid adaptability during initial dispersal across novel environments (Richards et al. 2012; Liebl et al. 2013). In male red grouse, environmental context affects T. tenuis burden by dictating how trade-offs between investment into parasite defence mechanisms and vital homeostatic mechanisms are resolved given testosterone-induced stress and social context (Sheldon \& Verhulst 1996; Bortolotti et al. 2009; Mougeot et al. 2010b; Vergara \& Martínez-Padilla 2012; Vergara et al. 2012a,b; Martínez-Padilla et al. 2014b). An epigenetic role in affecting T. tenuis burden has been suggested from associations of epigenetic variation with individual T. tenuis burden and population-level signatures of parasite-driven selection across this same landscape (Wenzel \& Piertney 2014), whereas such population-level signatures are inconsistent in candidate genes (Wenzel \& Piertney 2015). As such, plastic epigenetic responses could buffer selection pressure on genotypic information following dispersal across this landscape system, at least in the short term.

Fourth, irrespective of the degree of dispersal and gene flow, population-level patterns could further be obscured if parasite-driven selection is too weak to out-compete random genetic drift in driving population allele-frequency shifts. The provision of medicated grit reduces nematode burdens to low levels that are unlikely to impose the same severe fitness penalties as burdens above several thousand worms (Watson et al. 1987; Newborn \& Foster 2002; Martínez-Padilla et al. 2014a). As such, the fitness impact imposed by nematode infection may well be ameliorated such that selection is not strong enough to promote a population genetic signature. However, the median nematode burdens even in medicated areas were high enough to expect adaptive gene expression responses (Webster et al. 2011b), suggesting that selection should still maintain beneficial alleles among individuals (Wenzel \& Piertney 2015).

Finally, population-level patterns may be undetectable if selection is polygenic, acting on a phenotype with a complex genomic architecture that may not necessarily undergo adaptation through strong frequency shifts of small numbers of alleles, but instead through small allele frequency changes across many loci (Pritchard \& Di Rienzo 2010; Yeaman \& Whitlock 2011; Berg \& Coop 2014). Such architectures may still allow for detecting individual-based allelic effects, but $F_{\mathrm{ST}}$ outlier tests are unable to detect selection in polygenic architectures. For this reason, several case studies on complex phenotypes such as migratory behaviour in trout and salmon species have focused primarily on individualbased models rather than $F_{\mathrm{ST}}$ outlier tests (Narum et al. 2011; Hess \& Narum 2011; Narum et al. 2013; Johnston et al. 2014; Matala et al. 2014), or employed novel methods for detecting polygenic selection (Bourret et al. 2014). T. tenuis burden in red grouse may

This article is protected by copyright. All rights reserved. 
be based to a substantial degree on many loci of individually small effect (Wenzel et al. 2015), but there is also evidence for individual SNPs and candidate genes of large effect that would be expected to show classic signatures of selection (Wenzel \& Piertney 2015; Wenzel et al. 2015). Instead, the presence of $F_{\text {ST }}$ outlier SNPs that were not associated with parasite burden suggests that some other form of selection must have been potent enough to drive the identified signatures of selection. This re-emphasises the key issue that relying on a "population-to-individual" strategy centred on $F_{\mathrm{ST}}$ outlier tests would not have detected any candidates for parasite-driven selection, contrary to evidence from individual-based GWAS.

Notwithstanding the absence of parasite-driven selection, the population-level and individual-level analyses following $F_{\text {ST }}$ outlier tests have highlighted interesting contrasting geographic patterns of neutral and adaptive genetic structure. Such contrasting patterns are frequently reported and provide insight into adaptive evolution (e.g., Limborg et al. 2012; Matala et al. 2014; Milano et al. 2014, but see Moore et al. 2014). Consistent with microsatellite data, neutral genetic structure exhibited a weak latitudinal discontinuity driven by unsuitable habitat along a major river bisecting the landscape (Piertney et al. 1998). However, this signal was overshadowed by a stronger longitudinal signal, which was predominantly driven by the three easternmost sites at Tillypronie and Glen Dye. These sites also exhibited strong adaptive genetic structure. The original microsatellite study did not include Glen Dye sites, but still detected a similar longitudinal gradient, particularly among southern sites (Piertney et al. 1998). While Tillypronie is predominantly bounded by woodland and farmland relatively isolated from the main moors further west, Glen Dye represents the eastern edge of a semi-continuous upland moor landscape that includes the proximate sites in Invermark, Glen Muick and Airlie. This suggests that habitat edge effects in addition to previously identified dispersal barriers may play an important role in affecting evolutionary processes in red grouse. The presence of $F_{\mathrm{ST}}$ outlier SNPs unrelated to T. tenuis and the identified strong adaptive genetic structure among individuals within populations reinforces the potential for exploring other potential drivers of landscape genomic structure in red grouse. Identifying individual environmental drivers will require rigorous fine-scale quantification of biotic and abiotic environmental factors such as population density, predatory pressure, altitude, landscape resistance, habitat discontinuities and microclimate (Row et al. 2015).

In summary, this study contributes to our understanding of the genomic basis of host-parasite interactions in red grouse, and offers a warning about the conceptual and biological difficulties associated with examining signatures of natural selection associated with a complex phenotype in a landscape genomics context. Our previous molecular work on this study system has provided the robust and consistent picture that variation in $T$. tenuis burden among individual grouse can be explained by transcriptomic, genomic and epigenomic effects across multiple loci (Webster et al. 2011a; Wenzel et al. 2013; Wenzel

This article is protected by copyright. All rights reserved. 
\& Piertney 2014, 2015; Wenzel et al. 2015). These signatures, however, become diluted or lost at a population level as any differences in genotype frequencies that would be generated by variation in prevailing parasite burden are swamped by the effects of gene flow and multiple other environmental factors that influence the spatio-temporal patterns of standing genetic variation . This disparity between population-level and individual-level adaptive variation presents a real challenge to the power and utility of landscape genomics for detecting signatures of selection against the stochastic genomic background introduced by dispersal. The promise of landscape genomics is that it will deliver comprehensive insight into how environmental factors drive selection to shape genetic diversity, and offer a new mechanism for delineating populations for management and conservation based upon adaptive genetic differences (Joost et al. 2007, 2013; Manel et al. 2010; Parisod \& Holderegger 2012; Schoville et al. 2012; Matala et al. 2014). This can only be achieved when adaptive differences among individuals can be translated into differences among populations to arrive at a consistent picture of genomic signatures of natural selection. The red grouse case study demonstrates that this may not necessarily be the case and suggest that individual-based approaches such as linear genotype-environment modelling and genome-wide association may provide more robust insights than population-based methods. Such approaches may ultimately be the key to disentangling how multiple environmental factors conspire to promote conflicting types of genomic adaptive signatures by natural selection acting on complex, potentially polygenic phenotypes (Pritchard \& Di Rienzo 2010; Berg \& Coop 2014; Bourret et al. 2014).

This article is protected by copyright. All rights reserved. 
Table 1: Sampling locations, sample sizes $(\mathrm{M}=$ male, $\mathrm{F}=$ female, $\mathrm{Y}=$ young $)$ and nematode burdens (median worms per bird with $25 \%$ and $75 \%$ quantiles).

\begin{tabular}{|c|c|c|c|c|c|c|c|c|c|c|c|}
\hline \multicolumn{4}{|c|}{ Sampling locations } & \multicolumn{5}{|c|}{ Sample sizes } & \multicolumn{3}{|c|}{ Worms per bird } \\
\hline Site & Estate & Lat. & Long. & $\begin{array}{l}\text { Anthelmintic } \\
\text { grit }\end{array}$ & Total & M & $\mathrm{F}$ & $\mathrm{Y}$ & $25 \%$ & Median & $75 \%$ \\
\hline 1 & Glenlivet & 57.29 & -3.18 & Yes & 10 & 4 & 6 & 0 & 4 & 4 & 632 \\
\hline 2 & Glenlivet & 57.25 & -3.28 & Yes & 10 & 7 & 3 & 0 & 4 & 4 & 4 \\
\hline 3 & Edinglassie & 57.24 & -3.20 & Yes & 10 & 6 & 4 & 0 & 4 & 4 & 4 \\
\hline 4 & Edinglassie & 57.21 & -3.19 & Yes & 10 & 7 & 3 & 0 & 4 & 4 & 4 \\
\hline 5 & Allargue & 57.19 & -3.29 & Yes & 9 & 4 & 5 & 0 & 4 & 4 & 4 \\
\hline 6 & Allargue & 57.19 & -3.23 & Yes & 10 & 6 & 4 & 10 & 4 & 4 & 4 \\
\hline 7 & Delnadamph & 57.16 & -3.26 & No & 10 & 5 & 5 & 0 & 380 & 582 & 1394 \\
\hline 8 & Delnadamph & 57.14 & -3.30 & No & 10 & 8 & 2 & 0 & 978 & 1237 & 1837 \\
\hline 9 & Invercauld & 57.10 & -3.29 & Yes & 10 & 3 & 7 & 5 & 4 & 513 & 1586 \\
\hline 10 & Invercauld & 57.08 & -3.35 & Yes & 10 & 5 & 5 & 5 & 150 & 500 & 2264 \\
\hline 11 & Dinnet & 57.12 & -3.11 & Yes & 10 & 8 & 2 & 0 & 4 & 40 & 112 \\
\hline 12 & Dinnet & 57.11 & -3.06 & Yes & 10 & 6 & 4 & 0 & 4 & 180 & 556 \\
\hline 13 & Tillypronie & 57.18 & -2.94 & Yes & 9 & 3 & 6 & 8 & 4 & 78 & 200 \\
\hline 14 & Mar Lodge & 56.95 & -3.66 & No & 10 & 6 & 4 & 4 & 263 & 644 & 1400 \\
\hline 15 & Invercauld & 56.87 & -3.40 & Yes & 15 & 12 & 3 & 0 & 222 & 626 & 1159 \\
\hline 16 & Airlie & 56.81 & -3.08 & No & 18 & 13 & 5 & 0 & 812 & 2222 & 4069 \\
\hline 17 & Glen Muick & 56.99 & -3.01 & Yes & 20 & 11 & 9 & 0 & 674 & 1586 & 2609 \\
\hline 18 & Invermark & 56.94 & -2.89 & Yes & 10 & 6 & 4 & 0 & 600 & 1084 & 1380 \\
\hline 19 & Invermark & 56.89 & -2.89 & Yes & 10 & 4 & 6 & 0 & 232 & 603 & 694 \\
\hline 20 & Glen Dye & 56.95 & -2.72 & No & 10 & 6 & 4 & 5 & 372 & 813 & 1141 \\
\hline 21 & Glen Dye & 56.96 & -2.69 & No & 10 & 6 & 4 & 5 & 358 & 1006 & 1566 \\
\hline & & & & & 231 & 136 & 95 & 42 & & & \\
\hline
\end{tabular}

Table 2: Results of Bayesian regression of multi-locus population-specific local $F_{\mathrm{ST}}$ on combinations of longitude, latitude, anthelmintic medication regimen and T. tenuis burden predictors. The predictor combination of the model with the greatest posterior likelihood is indicated for neutral and outlier SNPs separately. Posterior likelihoods of all individual predictors are presented below and emboldened if part of the most likely model.

$$
\text { Neutral structure Adaptive structure }
$$

\begin{tabular}{lll}
\hline \hline Best model & & \\
Predictors & constant + longitude & constant \\
$P$ (model) & 0.235 & 0.377 \\
$\quad$ Likelihoods of predictors & & \\
Longitude & $\mathbf{0 . 5 4 1}$ & 0.307 \\
Latitude & 0.204 & 0.403 \\
Medication regimen & 0.186 & 0.122 \\
T. tenuis burden & 0.144 & 0.140 \\
\hline
\end{tabular}

This article is protected by copyright. All rights reserved. 
Table 3: Isolation-by-distance and isolation-by-stressor analysis results based on Mantel tests or distance based redundancy analysis (dbRDA) on multi-locus neutral and adaptive genetic structure among populations. Mantel correlation coefficients $(r)$, adjusted $R^{2}$ of RDA models and statistical significance $(P)$ are presented for models explaining genetic differentiation among population pairs $\left(G_{\mathrm{ST}}\right)$ by either geographic distance $(\mathrm{A})$ or differences in longitude (B), latitude (C), T. tenuis burden (D), medication regimen (E), medication regimen conditioned by geographic distance $(\mathrm{F})$ and T. tenuis burden conditioned by medication regimen and geographic distance $(\mathrm{G})$. Statistically significant correlation coefficients are emboldened.

\begin{tabular}{lcllllll}
\multicolumn{2}{l}{ Neutral structure } & \multicolumn{4}{l}{ Adaptive structure } \\
\hline \multicolumn{2}{l}{ Mantel tests } & dbRDA & & \multicolumn{3}{l}{ Mantel tests } & \multicolumn{2}{l}{ dbRDA } \\
\hline$r$ & $P$ & $R^{2}$ & $P$ & $r$ & $P$ & $R^{2}$ & $P$ \\
\hline
\end{tabular}

\begin{tabular}{lllllllll}
\hline \hline Isolation by distance & & & & & & & & \\
$\log _{10}$ geographic distance & $\mathbf{0 . 3 3 1}$ & 0.003 & 0.096 & 0.057 & -0.054 & 0.609 & 0.026 & 0.277 \\
longitude & $\mathbf{0 . 3 5 1}$ & 0.009 & 0.056 & 0.075 & 0.003 & 0.982 & 0.023 & 0.213 \\
latitude & 0.130 & 0.225 & $\mathbf{0 . 0 7 1}$ & 0.047 & -0.138 & 0.132 & -0.019 & 0.628 \\
$\quad$ Isolation by stressor & & & & & & & & \\
$\log _{10} T$. tenuis burden & -0.070 & 0.439 & -0.006 & 0.436 & -0.073 & 0.370 & -0.013 & 0.539 \\
medication regimen & 0.135 & 0.250 & 0.020 & 0.204 & 0.030 & 0.761 & -0.010 & 0.504 \\
medication regimen conditioned & 0.083 & 0.466 & -0.018 & 0.634 & 0.040 & 0.672 & 0.012 & 0.293 \\
by $\log _{10}$ geographic distance & & & & & & & & \\
$\log _{10} T$. tenuis burden & -0.186 & 0.101 & 0.027 & 0.180 & -0.062 & 0.528 & -0.027 & 0.704 \\
conditioned by medication & & & & & & & & \\
regimen and log geographic & & & & & & & & \\
distance & & & & & & & & \\
$\log _{10} T$. tenuis burden & -0.051 & 0.578 & -0.029 & 0.832 & -0.077 & 0.356 & 0.038 & 0.145 \\
conditioned by medication & & & & & & & & \\
regimen and longitude & & & & & & & & \\
$\log _{10} T$. tenuis burden & -0.173 & 0.120 & 0.012 & 0.248 & -0.002 & 0.986 & -0.035 & 0.811 \\
conditioned by medication & & & & & & & & \\
regimen and latitude & & & & & & & & \\
\hline
\end{tabular}

This article is protected by copyright. All rights reserved. 


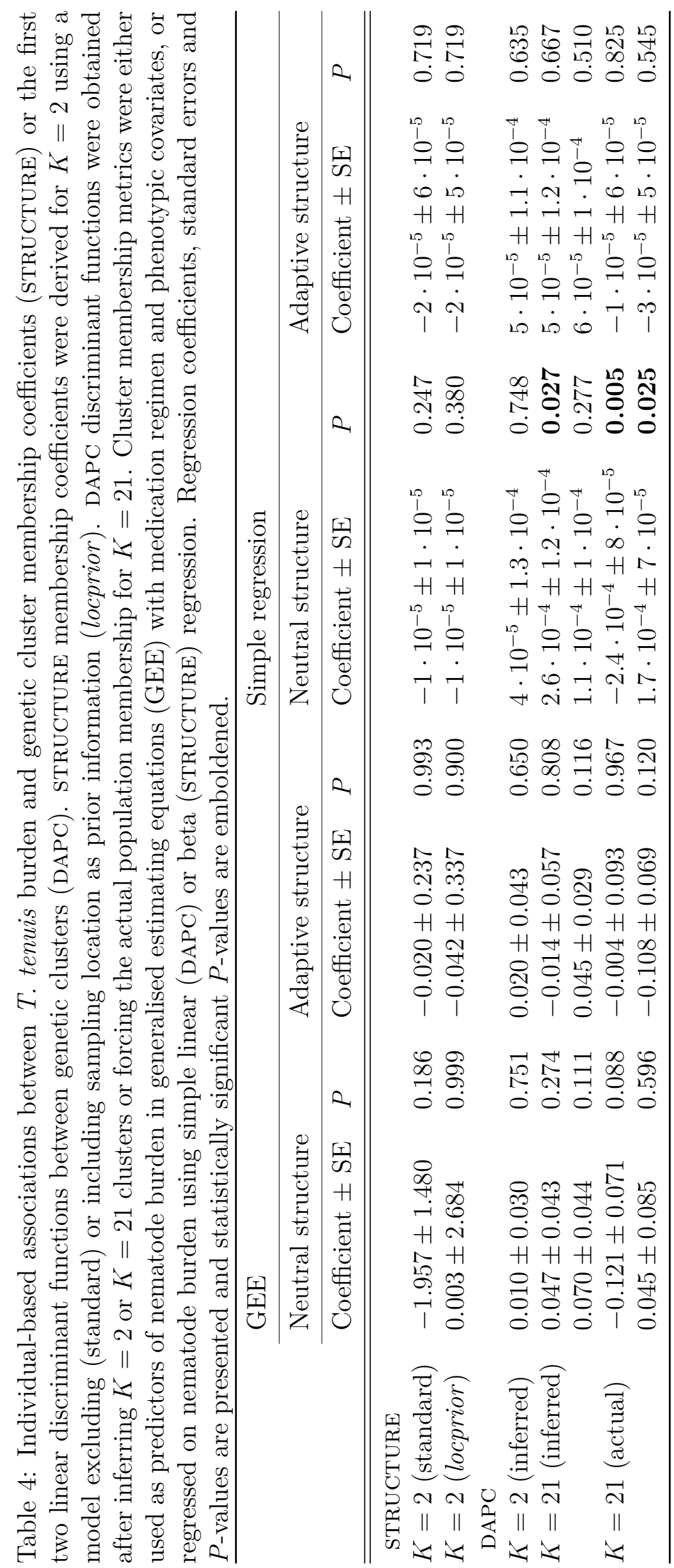

This article is protected by copyright. All rights reserved. 

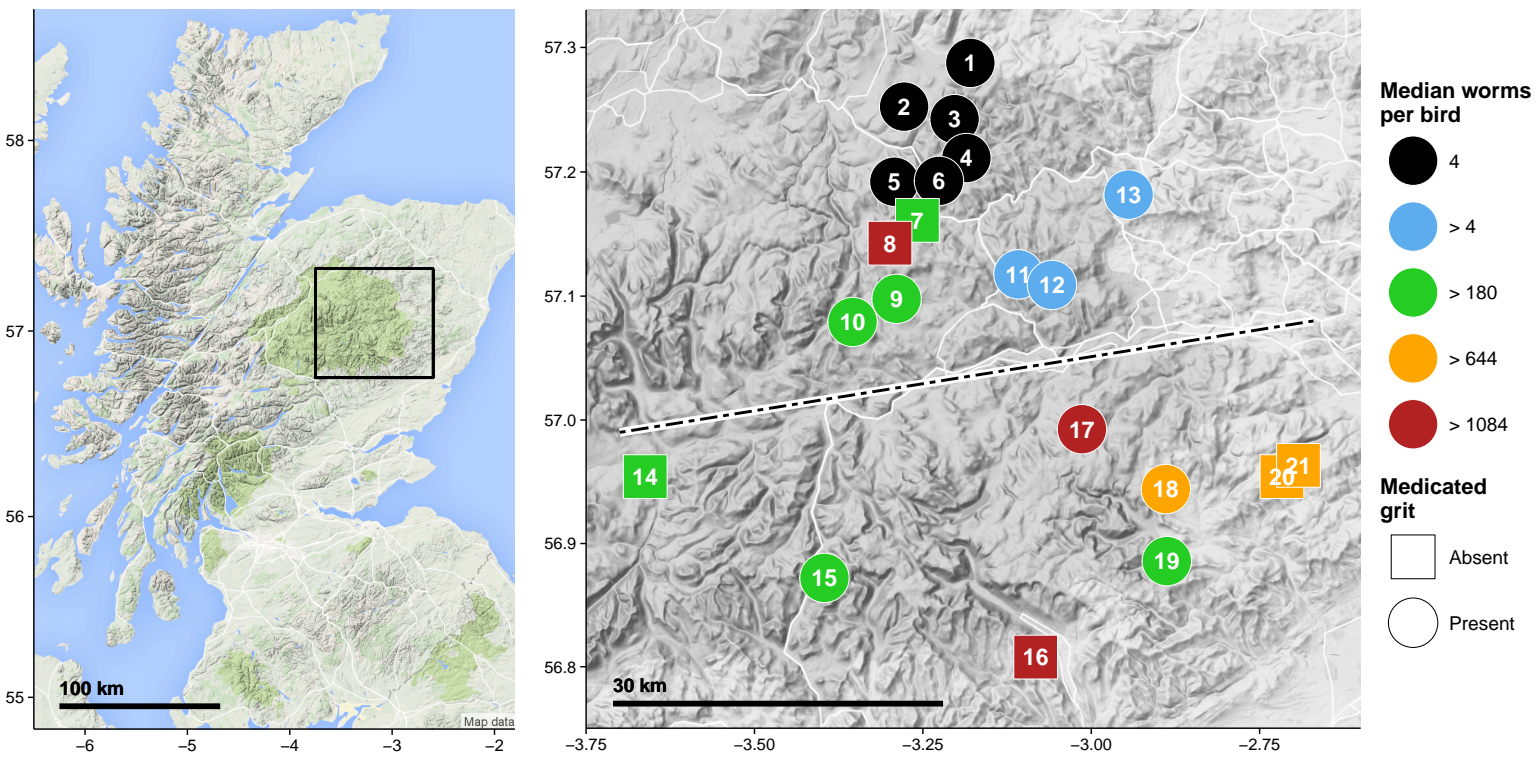

Figure 1: Sampling sites in north-east Scotland (Aberdeenshire, Angus and Moray). Median T. tenuis burden of sampled red grouse (Lagopus lagopus scotica) at each site is indicated by five colour categories, and the presence or absence of anthelmintic grit is indicated by symbol shape. The dashed line represents a previously identified barrier to dispersal associated with unsuitable habitat along the river Dee (Piertney et al. 1998). Detailed locations, sample sizes and nematode burdens are given in Table 1. Maps were retrieved from GoogleMaps using ggmap (Kahle \& Wickham 2013).

This article is protected by copyright. All rights reserved. 


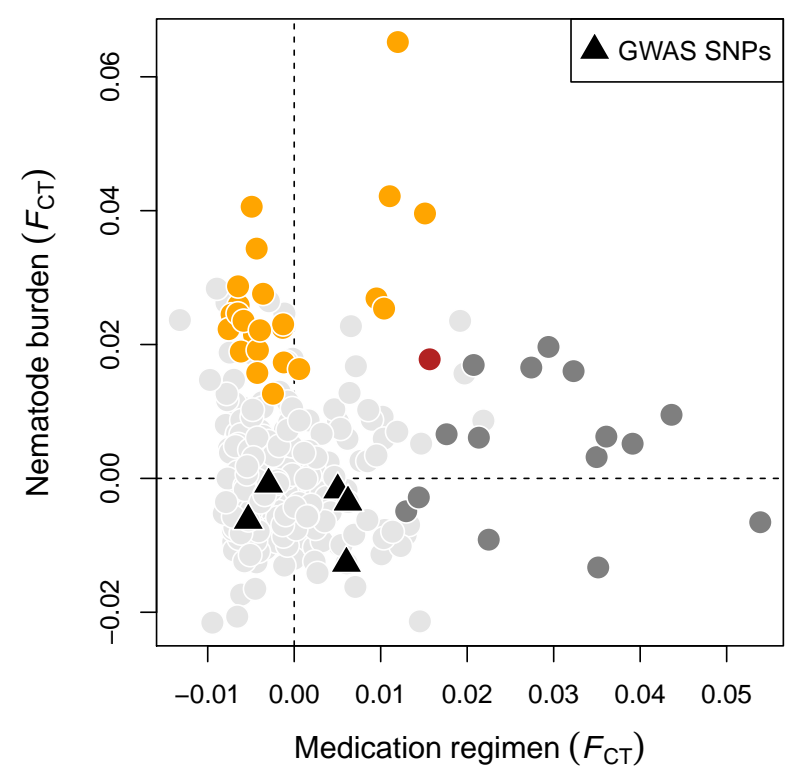

Figure 2: Graphical summary of SNP-by-SNP hierarchical AMOVA analysis testing for genetic differentiation among populations grouped by median nematode burden or anthelmintic medication regimen. Each data point represents the degree of genetic differentiation among population groups $\left(F_{\mathrm{CT}}\right)$ at a single SNP. Statistically significant $F_{\mathrm{CT}}$ estimates (single-test $P \leq 0.05$ ) are colour-coded (dark gray: medication regimen; orange: nematode burden; red: both; all SNPs not significant with FDR-corrected $q>0.1$ ). Five candidate SNPs for nematode-driven selection previously highlighted by genome-wide association (GWAS SNPs) are displayed as black triangles.

This article is protected by copyright. All rights reserved. 

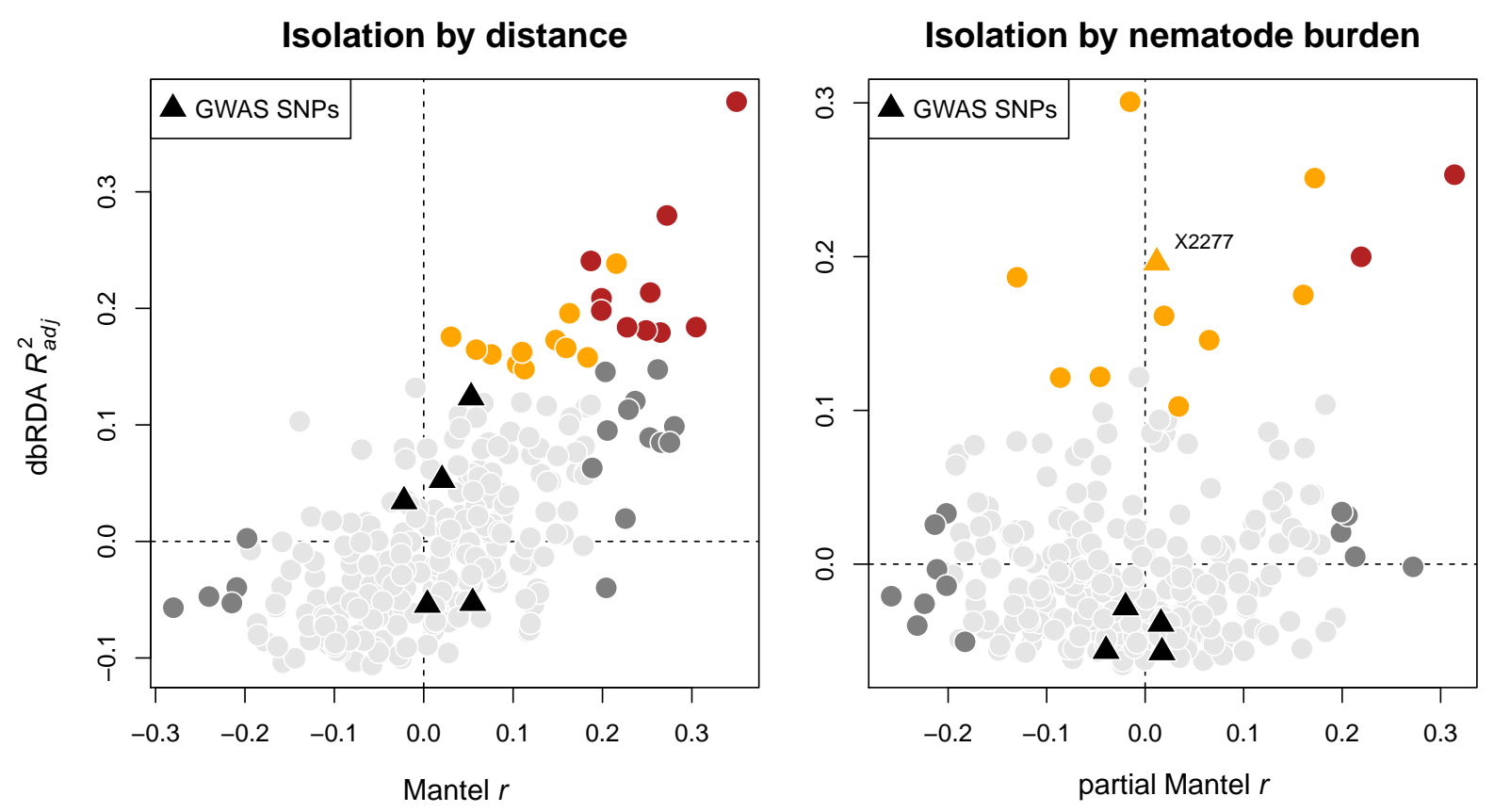

Figure 3: Graphical summaries of SNP-by-SNP Mantel tests and distance-based redundancy analysis (dbRDA), testing for association of genetic differentiation among population pairs $\left(G_{\mathrm{ST}}\right)$ with geographic distance (isolation by distance) or nematode burden (isolation by stressor). Each data point represents the Mantel matrix correlation coefficient $r$ and the adjusted $R^{2}$ of dbRDA for a single SNP. Isolation by distance was based on logarithmic geographic distance (Mantel tests) or longitude/latitude variables (dbRDA). Isolation by nematode burden was based on logarithmic nematode burden, conditioned by medication regimen and geographic variables. Statistically significant correlations (single-test $P \leq 0.05$ ) are colour-coded (dark gray: Mantel $r$; orange: dbRDA $R^{2}$; red: both; all SNPs not significant with FDR-corrected $q>0.1$ ) and the five GWAS SNPs are highlighted as black triangles.

This article is protected by copyright. All rights reserved. 


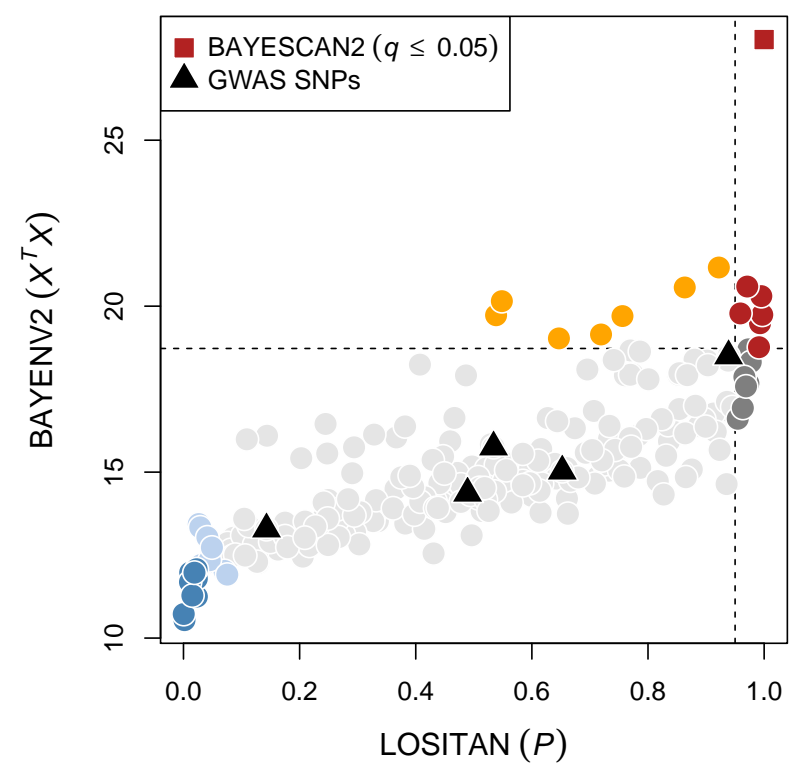

Figure 4: Graphical summary of genome scan results using three types of $F_{\text {ST }}$ outlier tests. Each data point represents the relative degree of genetic differentiation among 21 sampling sites of a single SNP, using LOSITAN and BAYENV2. SNPs that were also significant outliers in BAYESCAN2 are displayed as squares. Dashed lines represent the liberal $P=0.95$ threshold for directional selection in LOSITAN and the analogous 95th percentile threshold $\left(X^{T} X>19\right)$ for BAYENV2. SNPs beyond either of these thresholds are suggestive outliers (orange: BAYENV2; dark gray: LOSITAN), and SNPs beyond both thresholds are robust outliers (red). For comparison, hypothetical candidate SNPs for balancing selection below $P=0.05$ or $X^{T} X<12$ (5th percentile) thresholds are indicated in light blue (either threshold) and dark blue (both thresholds). The five GWAS SNPs are highlighted as black triangles.
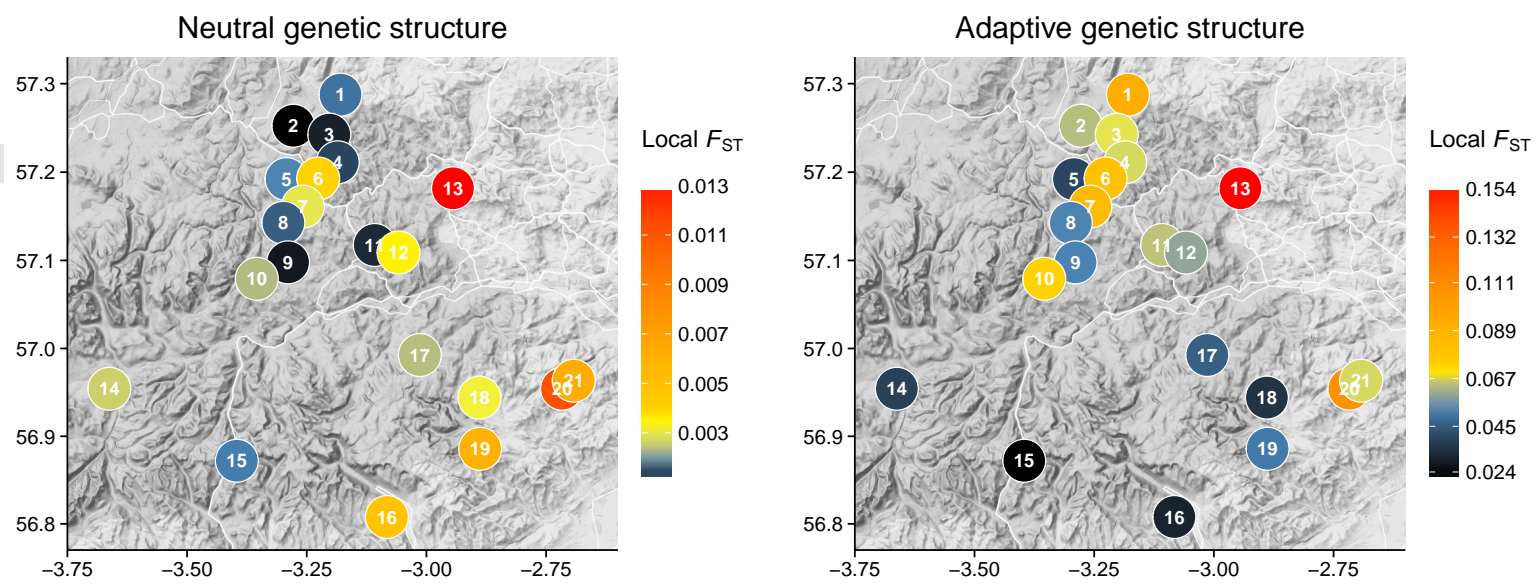

Figure 5: Geographic patterns of neutral and adaptive genetic structure (populationspecific local $F_{\mathrm{ST}}$ based on 251 neutral SNPs or $7 F_{\mathrm{ST}}$ outlier SNPs) across a landscape of 21 populations. Mean posterior local $F_{\mathrm{ST}}$ is indicated using a heat colour scale with break points following $F_{\mathrm{ST}}$ quartiles to provide higher colour resolution at the low end. Maps were retrieved from GoogleMaps using ggmap (Kahle \& Wickham 2013).

This article is protected by copyright. All rights reserved. 


\section{Acknowledgements}

This study was funded by a BBSRC studentship (MAW) and NERC grants NE/H00775X/1 and NE/D000602/1 (SBP). The authors are grateful to Mario Röder and Keliya Bai for fieldwork assistance, and all estate owners, factors and keepers for access to field sites, most particularly MJ Taylor and Mike Nisbet (Airlie), Neil Brown (Allargue), RR Gledson and David Scrimgeour (Delnadamph), Andrew Salvesen and John Hay (Dinnet), Stuart Young and Derek Calder (Edinglassie), Kirsty Donald and David Busfield (Glen Dye), Neil Hogbin and Ab Taylor (Glen Muick), Alistair Mitchell (Glenlivet), Simon Blackett, Jim Davidson and Liam Donald (Invercauld), Richard Cooke and Fred Taylor $†$ (Invermark), Shaila Rao and Christopher Murphy (Mar Lodge), and Ralph Peters and Philip Astor (Tillypronie).

\section{Supplementary data}

- Figure S1: Graphical summary of $G_{\mathrm{ST}}$ among population pairs

- Figure S2: Posterior likelihood and Evanno's $\Delta \mathrm{K}$ plots for STRUCTURE runs

- Figure S3: K-means clustering results for DAPC analysis

\section{Data accessibility}

- Genotype data (DataDryad: doi:10.5061/dryad.4t7jk)

- Metadata (information on sampling sites, phenotypes and medication regimen) (DataDryad: doi:10.5061/dryad.4t7jk)

\section{Author contributions}

SBP and SMR conceived and designed the study. MAW performed field and lab work. AD and MCJ developed SNP markers. MAW analysed the data. MAW and SBP wrote the manuscript.

\section{Ethics statement}

The sampled grouse were shot by hunters during organised sporting shoots and not for the sole purpose of research. The authors were not involved in the shooting.

This article is protected by copyright. All rights reserved. 


\section{References}

Andrew RL, Bernatchez L, Bonin A et al. (2013) A road map for molecular ecology. Molecular Ecology, 22, 2605-2626.

Antao T, Lopes A, Lopes RJ, Beja-Pereira A, Luikart G (2008) LOSITAN: a workbench to detect molecular adaptation based on a Fst-outlier method. BMC Bioinformatics, $\mathbf{9}$, 323.

Bashalkhanov S, Eckert AJ, Rajora OP (2013) Genetic signatures of natural selection in response to air pollution in red spruce (Picea rubens, Pinaceae). Molecular Ecology, 22, $5877-5889$.

Beaumont MA, Nichols RA (1996) Evaluating loci for use in the genetic analysis of population structure. Proceedings of the Royal Society B: Biological Sciences, 263, 1619-1626.

Benjamini Y, Hochberg Y (1995) Controlling the False Discovery Rate: a Practical and Powerful Approach to Multiple Testing. Journal of the Royal Statistical Society: Series $B, \mathbf{5 7}, 289-300$.

Berg JJ, Coop G (2014) A population genetic signal of polygenic adaptation. PLoS Genetics, 10, e1004412.

Bortolotti GR, Mougeot F, Martínez-Padilla J, Webster LMI, Piertney SB (2009) Physiological stress mediates the honesty of social signals. PLoS ONE, 4, e4983.

Bossdorf O, Richards CL, Pigliucci M (2008) Epigenetics for ecologists. Ecology Letters, 11, 106-115.

Bourret V, Dionne M, Bernatchez L (2014) Detecting genotypic changes associated with selective mortality at sea in Atlantic salmon: polygenic multilocus analysis surpasses genome scan. Molecular Ecology, 23, 4444-4457.

Coop G, Witonsky D, Di Rienzo A, Pritchard JK (2010) Using environmental correlations to identify loci underlying local adaptation. Genetics, 185, 1411-1423.

Cox R, Newborn D, Baines D, Thomas CJ, Sherratt TN (2010) No evidence for resistance to fenbendazole in Trichostrongylus tenuis, a nematode parasite of the red grouse. Journal of Wildlife Management, 74, 1799-1805.

Cribari-Neto F, Zeileis A (2010) Beta regression in R. Journal of Statistical Software, 34, $1-24$.

De Mita S, Thuillet AC, Gay L et al. (2013) Detecting selection along environmental gradients: analysis of eight methods and their effectiveness for outbreeding and selfing populations. Molecular Ecology, 22, 1383-1399.

Delahay RJ, Moss R (1996) Food intake, weight changes and egg production in captive red grouse before and during laying: effects of the parasitic nematode Trichostrongylus tenuis. The Condor, 98, 501-511.

This article is protected by copyright. All rights reserved. 
Delahay RJ, Speakman JR, Moss R (1995) The energetic consequences of parasitism: effects of a developing infection of Trichostrongylus tenuis (Nematoda) on red grouse (Lagopus lagopus scoticus) energy balance, body weight and condition. Parasitology, 110, 473-482.

Duncan EJ, Gluckman PD, Dearden PK (2014) Epigenetics, plasticity, and evolution: How do we link epigenetic change to phenotype? Journal of Experimental Zoology Part B: Molecular and Developmental Evolution, 322, 208-220.

Earl DA, vonHoldt BM (2012) STRUCTURE HARVESTER: a website and program for visualizing STRUCTURE output and implementing the Evanno method. Conservation Genetics Resources, 4, 359-361.

Ellegren H (2014) Genome sequencing and population genomics in non-model organisms. Trends in Ecology \& Evolution, 29, 51-63.

Evanno G, Regnaut S, Goudet J (2005) Detecting the number of clusters of individuals using the software STRUCTURE: a simulation study. Molecular Ecology, 14, 2611-2620.

Excoffier L, Lischer HE (2010) Arlequin suite ver 3.5: a new series of programs to perform population genetics analyses under Linux and Windows. Molecular Ecology Resources, 10, 564-567.

Excoffier L, Smouse PE, Quattro JM (1992) Analysis of molecular variance inferred from metric distances among DNA haplotypes: application to human mitochondrial DNA restriction data. Genetics, 131, 479-491.

Falush D, Stephens M, Pritchard JK (2003) Inference of Population Structure Using Multilocus Genotype Data: Linked Loci and Correlated Allele Frequencies. Genetics, 164, 1567-1587.

Foll M, Gaggiotti O (2006) Identifying the environmental factors that determine the genetic structure of populations. Genetics, 174, 875-891.

Foll M, Gaggiotti O (2008) A genome-scan method to identify selected loci appropriate for both dominant and codominant markers: a Bayesian perspective. Genetics, 180, 977-993.

Fox A, Hudson PJ (2001) Parasites reduce territorial behaviour in red grouse (Lagopus lagopus scoticus). Ecology Letters, 4, 139-143.

Gaggiotti OE, Foll M (2010) Quantifying population structure using the F-model. Molecular Ecology Resources, 10, 821-830.

Günther T, Coop G (2013) Robust Identification of Local Adaptation from Allele Frequencies. Genetics, 195, 205-220.

Goslee SC, Urban DL (2007) The ecodist package for dissimilarity-based analysis of ecological data. Journal of Statistical Software, 22, 1-19.

Griffiths R, Double MC, Orr K, Dawson RJ (1998) A DNA test to sex most birds. Molecular Ecology, 7, 1071-1075.

This article is protected by copyright. All rights reserved. 
Halekoh U, Højsgaard S, Yan J (2006) The R package geepack for generalized estimating equations. Journal of Statistical Software, 15, 1-11.

Hess JE, Campbell NR, Close DA, Docker MF, Narum SR (2013) Population genomics of pacific lamprey: adaptive variation in a highly dispersive species. Molecular Ecology, 22, 2898-2916.

Hess JE, Narum SR (2011) Single-nucleotide polymorphism (SNP) loci correlated with run timing in adult Chinook salmon from the Columbia River basin. Transactions of the American Fisheries Society, 140, 855-864.

Hogan FE, Cooke R, Burridge CP, Norman JA (2008) Optimizing the use of shed feathers for genetic analysis. Molecular Ecology Resources, 8, 561-567.

Hubbard AE, Ahern J, Fleischer NL et al. (2010) To GEE or not to GEE: comparing population average and mixed models for estimating the associations between neighborhood risk factors and health. Epidemiology, 21, 467-474.

Hubisz MJ, Falush D, Stephens M, Pritchard JK (2009) Inferring weak population structure with the assistance of sample group information. Molecular Ecology Resources, 9, $1322-1332$.

Hudson PJ (1986) The effect of a parasitic nematode on the breeding production of red grouse. Journal of Animal Ecology, 55, 85-92.

Hudson PJ, Dobson AP, Newborn D (1992a) Do parasites make prey vulnerable to predation? Red grouse and parasites. Journal of Animal Ecology, 61, 681-692.

Hudson PJ, Dobson AP, Newborn D (1998) Prevention of population cycles by parasite removal. Science, 282, 2256-2258.

Hudson PJ, Newborn D, Dobson AP (1992b) Regulation and stability of a free-living host-parasite system: Trichostrongylus tenuis in red grouse. I. Monitoring and parasite reduction experiments. Journal of Animal Ecology, 61, 477-486.

Jakobsson M, Rosenberg NA (2007) CLUMPP: a cluster matching and permutation program for dealing with label switching and multimodality in analysis of population structure. Bioinformatics, 23, 1801-1806.

Jenkins D, Watson A, Miller G (1963) Population studies on red grouse, Lagopus lagopus scoticus (Lath.) in north-east Scotland. The Journal of Animal Ecology, 317-376.

Johnston SE, Orell P, Pritchard VL et al. (2014) Genome-wide SNP analysis reveals a genetic basis for sea-age variation in a wild population of Atlantic salmon (Salmo salar). Molecular Ecology, 23, 3452-3468.

Jombart $\mathrm{T}$ (2008) adegenet: a $\mathrm{R}$ package for the multivariate analysis of genetic markers. Bioinformatics, 24, 1403-1405.

Jombart T, Ahmed I (2011) adegenet 1.3-1: new tools for the analysis of genome-wide SNP data. Bioinformatics, 27, 3070-3071.

This article is protected by copyright. All rights reserved. 
Jombart T, Devillard S, Balloux F (2010) Discriminant analysis of principal components: a new method for the analysis of genetically structured populations. BMC Genetics, 11, 94 .

Joost S, Bonin A, Bruford MW et al. (2007) A spatial analysis method (SAM) to detect candidate loci for selection: towards a landscape genomics approach to adaptation. Molecular Ecology, 16, 3955-3969.

Joost S, Kalbermatten M, Bonin A (2008) Spatial analysis method (SAM): a software tool combining molecular and environmental data to identify candidate loci for selection. Molecular Ecology Resources, 8, 957-960.

Joost S, Vuilleumier S, Jensen JD et al. (2013) Uncovering the genetic basis of adaptive change: on the intersection of landscape genomics and theoretical population genetics. Molecular Ecology, 22, 3659-3665.

Kahle D, Wickham H (2013) ggmap: Spatial Visualization with ggplot2. The $R$ Journal, 5, 144-161.

Keenan K, McGinnity P, Cross TF, Crozier WW, Prodöhl PA (2013) diveRsity: An R package for the estimation and exploration of population genetics parameters and their associated errors. Methods in Ecology and Evolution, 4, 782-788.

Kirk H, Freeland JR (2011) Applications and implications of neutral versus non-neutral markers in molecular ecology. International Journal of Molecular Sciences, 12, 39663988.

Konijnendijk N, Shikano T, Daneels D, Volckaert FA, Raeymaekers JA (2015) Signatures of selection in the three-spined stickleback along a small-scale brackish water-freshwater transition zone. Ecology and Evolution.

Legendre P, Fortin MJ (2010) Comparison of the mantel test and alternative approaches for detecting complex multivariate relationships in the spatial analysis of genetic data. Molecular Ecology Resources, 10, 831-844.

Legendre P, Oksanen J, ter Braak CJ (2011) Testing the significance of canonical axes in redundancy analysis. Methods in Ecology and Evolution, 2, 269-277.

Lenormand T (2002) Gene flow and the limits to natural selection. Trends in Ecology \&6 Evolution, 17, 183-189.

Lewontin R, Krakauer J (1973) Distribution of gene frequency as a test of the theory of the selective neutrality of polymorphisms. Genetics, 74, 175-195.

Liebl AL, Schrey AW, Richards CL, Martin LB (2013) Patterns of DNA methylation throughout a range expansion of an introduced songbird. Integrative and Comparative Biology, 53, 351-358.

Limborg MT, Helyar SJ, de Bruyn M et al. (2012) Environmental selection on transcriptome-derived SNPs in a high gene flow marine fish, the Atlantic herring (Clupea harengus). Molecular Ecology, 21, 3686-3703.

This article is protected by copyright. All rights reserved. 
Lochmiller RL (1996) Immunocompetence and animal population regulation. Oikos, 594602.

Lotterhos KE, Whitlock MC (2014) Evaluation of demographic history and neutral parameterization on the performance of FST outlier tests. Molecular Ecology Resources, 23, 2178-2192.

Lotterhos KE, Whitlock MC (2015) The relative power of genome scans to detect local adaptation depends on sampling design and statistical method. Molecular Ecology.

MacColl ADC, Piertney SB, Moss R, Lambin X (2000) Spatial arrangement of kin affects recruitment success in young male red grouse. Oikos, 90, 261-270.

Manel S, Conord C, Després L (2009) Genome scan to assess the respective role of hostplant and environmental constraints on the adaptation of a widespread insect. $B M C$ Evolutionary Biology, 9, 288.

Manel S, Joost S, Epperson BK et al. (2010) Perspectives on the use of landscape genetics to detect genetic adaptive variation in the field. Molecular Ecology, 19, 3760-3772.

Manel S, Schwartz MK, Luikart G, Taberlet P (2003) Landscape genetics: combining landscape ecology and population genetics. Trends in Ecology \& Evolution, 18, 189197.

Martínez-Padilla J, Pérez-Rodríguez L, Mougeot F, Ludwig S, Redpath S (2014a) Experimentally elevated levels of testosterone at independence reduce fitness in a territorial bird. Ecology, 95, 1033-1044.

Martínez-Padilla J, Pérez-Rodríguez L, Mougeot F, Ludwig S, Redpath SM (2014b) Intrasexual competition alters the relationship between testosterone and ornament expression in a wild territorial bird. Hormones and Behavior, 65, 435-444.

Martínez-Padilla J, Redpath SM, Zeineddine M, Mougeot F (2014c) Insights into population ecology from long-term studies of red grouse Lagopus lagopus scoticus. Journal of Animal Ecology, 83, 85-98.

Martinez-Padilla J, Vergara P, Pérez-Rodríguez L et al. (2011) Condition-and parasitedependent expression of a male-like trait in a female bird. Biology Letters, 7, 364-367.

Martínez-Padilla J, Mougeot F, Pérez-Rodríguez L, Bortolotti GR (2007) Nematode parasites reduce carotenoid-based signalling in male red grouse. Biology Letters, 3, 161-164.

Martínez-Padilla J, Mougeot F, Webster LMI, Pérez-Rodríguez L, Piertney SB (2010) Testing the interactive effects of testosterone and parasites on carotenoid-based ornamentation in a wild bird. Journal of Evolutionary Biology, 23, 902-913.

Matala AP, Ackerman MW, Campbell MR, Narum SR (2014) Relative contributions of neutral and non-neutral genetic differentiation to inform conservation of steelhead trout across highly variable landscapes. Evolutionary Applications, 7, 682-701.

Matala AP, Hess JE, Narum SR (2011) Resolving adaptive and demographic divergence among Chinook salmon populations in the Columbia River Basin. Transactions of the American Fisheries Society, 140, 783-807.

This article is protected by copyright. All rights reserved. 
Milano I, Babbucci M, Cariani A et al. (2014) Outlier SNP markers reveal fine-scale genetic structuring across European hake populations (Merluccius merluccius). Molecular Ecology, 23, 118-135.

Moore JS, Bourret V, Dionne M et al. (2014) Conservation genomics of anadromous Atlantic salmon across its North American range: outlier loci identify the same patterns of population structure as neutral loci. Molecular Ecology, 23, 5680-5697.

Moss R, Watson A, Trenholm IB, Parr R (1993) Caecal threadworms Trichostrongylus tenuis in red grouse Lagopus lagopus scoticus: Effects of weather and host density upon estimated worm burdens. Parasitology, 107, 199-209.

Mougeot F, Evans SA, Redpath SM (2005a) Interactions between population processes in a cyclic species: Parasites reduce autumn territorial behaviour of male red grouse. Oecologia, 144, 289-298.

Mougeot F, Irvine JR, Seivwright L, Redpath SM, Piertney S (2004) Testosterone, immunocompetence, and honest sexual signaling in male red grouse. Behavioral Ecology, 15, 930-937.

Mougeot F, Martínez-Padilla J, Blount JD, Pérez-Rodríguez L, Webster LMI, Piertney SB (2010a) Oxidative stress and the effect of parasites on a carotenoid-based ornament. The Journal of Experimental Biology, 213, 400-407.

Mougeot F, Martínez-Padilla J, Bortolotti GR, Webster LMI, Piertney SB (2010b) Physiological stress links parasites to carotenoid-based colour signals. Journal of Evolutionary Biology, 23, 643-650.

Mougeot F, Martínez-Padilla J, Webster LMI, Blount JD, Pérez-Rodríguez L, Piertney SB (2009) Honest sexual signalling mediated by parasite and testosterone effects on oxidative balance. Proceedings of the Royal Society B: Biological Sciences, 276, 10931100 .

Mougeot F, Piertney SB, Leckie F et al. (2005b) Experimentally increased aggressiveness reduces population kin structure and subsequent recruitment in red grouse Lagopus lagopus scoticus. Journal of Animal Ecology, 74, 488-497.

Mougeot F, Pérez-Rodríguez L, Martínez-Padilla J, Leckie F, Redpath SM (2007) Parasites, testosterone and honest carotenoid-based signalling of health. Functional Ecology, 21, 886-898.

Mougeot F, Redpath SM, Leckie F (2005c) Ultra-violet reflectance of male and female red grouse, Lagopus lagopus scoticus: Sexual ornaments reflect nematode parasite intensity. Journal of Avian Biology, 36, 203-209.

Narum SR, Campbell NR, Meyer KA, Miller MR, Hardy RW (2013) Thermal adaptation and acclimation of ectotherms from differing aquatic climates. Molecular Ecology, 22, 3090-3097.

Narum SR, Hess JE (2011) Comparison of FST outlier tests for SNP loci under selection. Molecular Ecology Resources, 11, 184-194.

This article is protected by copyright. All rights reserved. 
Narum SR, Zendt JS, Frederiksen C, Campbell N, Matala A, Sharp WR (2011) Candidate genetic markers associated with anadromy in Oncorhynchus mykiss of the Klickitat River. Transactions of the American Fisheries Society, 140, 843-854.

Newborn D, Foster R (2002) Control of parasite burdens in wild red grouse Lagopus lagopus scoticus through the indirect application of anthelmintics. Journal of Applied Ecology, 39, 909-914.

Nielsen EE, Hemmer-Hansen J, Poulsen NA et al. (2009) Genomic signatures of local directional selection in a high gene flow marine organism; the Atlantic cod (Gadus morhua). BMC Evolutionary Biology, 9, 276.

Oksanen J, Blanchet FG, Kindt R et al. (2013) vegan: Community Ecology Package. R package version 2.0-10.

Orsini L, Mergeay J, Vanoverbeke J, Meester L (2013) The role of selection in driving landscape genomic structure of the waterflea daphnia magna. Molecular Ecology, 22, 583-601.

Orsini L, Spanier KI, De Meester L (2012) Genomic signature of natural and anthropogenic stress in wild populations of the waterflea Daphnia magna: validation in space, time and experimental evolution. Molecular Ecology, 21, 2160-2175.

Pariset L, Joost S, Marsan PA, Valentini A et al. (2009) Landscape genomics and biased FST approaches reveal single nucleotide polymorphisms under selection in goat breeds of North-East Mediterranean. BMC Genetics, 10, 7.

Parisod C, Holderegger R (2012) Adaptive landscape genetics: pitfalls and benefits. Molecular Ecology, 21, 3644-3646.

Pespeni MH, Palumbi SR (2013) Signals of selection in outlier loci in a widely dispersing species across an environmental mosaic. Molecular Ecology, 22, 3580-3597.

Piertney SB (2003) Major histocompatibility complex B-LB gene variation in red grouse Lagopus lagopus scoticus. Wildlife Biology, 9, 251-259.

Piertney SB, Lambin X, Maccoll ADC et al. (2008) Temporal changes in kin structure through a population cycle in a territorial bird, the red grouse Lagopus lagopus scoticus. Molecular Ecology, 17, 2544-2551.

Piertney SB, MacColl ADC, Bacon PJ, Dallas JF (1998) Local genetic structure in red grouse (Lagopus lagopus scoticus): Evidence from microsatellite DNA markers. Molecular Ecology, 7, 1645-1654.

Piertney SB, Maccoll ADC, Bacon PJ, Racey PA, Lambin X, Dallas JF (2000) Matrilineal genetic structure and female-mediated gene flow in red grouse (Lagopus lagopus scoticus): An analysis using mitochondrial DNA. Evolution, 54, 279-289.

Piertney SB, MacColl ADC, Lambin X, Moss R, Dallas JF (1999) Spatial distribution of genetic relatedness in a moorland population of red grouse (Lagopus lagopus scoticus). Biological Journal of the Linnean Society, 68, 317-331.

Poulin R (2007) Are there general laws in parasite ecology? Parasitology, 134, 763-776.

This article is protected by copyright. All rights reserved. 
Pritchard JK, Di Rienzo A (2010) Adaptation-not by sweeps alone. Nature Reviews Genetics, 11, 665-667.

Pritchard JK, Stephens M, Donnelly P (2000) Inference of Population Structure Using Multilocus Genotype Data. Genetics, 155, 945-959.

R Core Team (2014) R: A Language and Environment for Statistical Computing. R Foundation for Statistical Computing, Vienna, Austria.

Redpath SM, Mougeot F, Leckie FM, Elston DA, Hudson PJ (2006) Testing the role of parasites in driving the cyclic population dynamics of a gamebird. Ecology Letters, 9, 410-418.

Rellstab C, Gugerli F, Eckert AJ, Hancock AM, Holderegger R (2015) A practical guide to environmental association analysis in landscape genomics. Molecular Ecology.

Richards CL, Schrey AW, Pigliucci M (2012) Invasion of diverse habitats by few Japanese knotweed genotypes is correlated with epigenetic differentiation. Ecology Letters, 15, $1016-1025$.

Richter-Boix A, Quintela M, Segelbacher G, Laurila A (2011) Genetic analysis of differentiation among breeding ponds reveals a candidate gene for local adaptation in Rana arvalis. Molecular Ecology, 20, 1582-1600.

Row JR, Oyler-McCance SJ, Fike JA et al. (2015) Landscape characteristics influencing the genetic structure of greater sage-grouse within the stronghold of their range: a holistic modeling approach. Ecology and Evolution.

Saunders LM, Tompkins DM, Hudson PJ (1999) The dynamics of nematode transmission in the red grouse (Lagopus lagopus scoticus): Studies on the recovery of Trichostrongylus tenuis larvae from vegetation. Journal of Helminthology, 73, 171-175.

Schielzeth H, Husby A (2014) Challenges and prospects in genome-wide quantitative trait loci mapping of standing genetic variation in natural populations. Annals of the New York Academy of Sciences, 1320, 35-57.

Schoville SD, Bonin A, François O, Lobreaux S, Melodelima C, Manel S (2012) Adaptive genetic variation on the landscape: methods and cases. Annual Review of Ecology, Evolution, and Systematics, 43, 23-43.

Seivwright LJ, Redpath SM, Mougeot F, Watt L, Hudson PJ (2004) Faecal egg counts provide a reliable measure of Trichostrongylus tenuis intensities in free-living red grouse Lagopus lagopus scoticus. Journal of Helminthology, 78, 69-76.

Shaw JL, Moss R (1989) Factors affecting the establishment of the caecal threadworm Trichostrongylus tenuis in red grouse (Lagopus lagopus scoticus). Parasitology, 99, 259264.

Sheldon BC, Verhulst S (1996) Ecological immunology: costly parasite defences and tradeoffs in evolutionary ecology. Trends in Ecology \& Evolution, 11, 317-321.

Shikano T, Ramadevi J, Merilä J (2010) Identification of local-and habitat-dependent selection: scanning functionally important genes in nine-spined sticklebacks (Pungitius pungitius). Molecular Biology and Evolution, 27, 2775-2789.

This article is protected by copyright. All rights reserved. 
Slate J (2005) Quantitative trait locus mapping in natural populations: progress, caveats and future directions. Molecular Ecology, 14, 363-379.

Slatkin M (1987) Gene flow and the geographic structure of natural populations. Science, 236, 787-792.

Smouse PE, Long JC, Sokal RR (1986) Multiple regression and correlation extensions of the Mantel test of matrix correspondence. Systematic Zoology, 35, 627-632.

Storfer A, Murphy M, Evans J et al. (2007) Putting the 'landscape' in landscape genetics. Heredity, 98, 128-142.

Storz JF (2005) Using genome scans of DNA polymorphism to infer adaptive population divergence. Molecular Ecology, 14, 671-688.

Vergara P, Martínez-Padilla J (2012) Social context decouples the relationship between a sexual ornament and testosterone levels in a male wild bird. Hormones and Behavior, 62, 407-412.

Vergara P, Martínez-Padilla J, Mougeot F, Leckie F, Redpath SM (2012a) Environmental heterogeneity influences the reliability of secondary sexual traits as condition indicators. Journal of Evolutionary Biology, 25, 20-28.

Vergara P, Mougeot F, Martínez-Padilla J, Leckie F, Redpath SM (2012b) The condition dependence of a secondary sexual trait is stronger under high parasite infection level. Behavioral Ecology, 23, 502-511.

Vincent B, Dionne M, Kent MP, Lien S, Bernatchez L (2013) Landscape genomics in atlantic salmon (Salmo salar): searching for gene-environment interactions driving local adaptation. Evolution, 67, 3469-3487.

Watson A (1985) Social class, socially-induced loss, recruitment and breeding of red grouse. Oecologia, 67, 493-498.

Watson A, Moss R, Parr R, Mountford M, Rothery P (1994) Kin landownership, diffferential aggression between kin and non-kin, and population fluctuations in red grouse. Journal of Animal Ecology, 63, 39-50.

Watson H, Lee DL, Hudson PJ (1987) The effect of Trichostrongylus tenuis on the caecal mucosa of young, old and anthelmintic-treated wild red grouse, Lagopus lagopus scoticus. Parasitology, 94, 405-411.

Webster LM, Johnson PC, Adam A, Mable BK, Keller LF (2008) Absence of three known benzimidazole resistance mutations in Trichostrongylus tenuis, a nematode parasite of avian hosts. Veterinary Parasitology, 158, 302-310.

Webster LMI, Mello LV, Mougeot F, Martínez-Padilla J, Paterson S, Piertney SB (2011a) Identification of genes responding to nematode infection in red grouse. Molecular Ecology Resources, 11, 305-313.

Webster LMI, Paterson S, Mougeot F, Martínez-Padilla J, Piertney SB (2011b) Transcriptomic response of red grouse to gastro-intestinal nematode parasites and testosterone: Implications for population dynamics. Molecular Ecology, 20, 920-931.

This article is protected by copyright. All rights reserved. 
Wenzel MA, James MC, Douglas A, Piertney SB (2015) Genome-wide association and genome partitioning reveal novel genomic regions underlying variation in gastrointestinal nematode burden in a wild bird. Molecular Ecology, 24, 4175-4192.

Wenzel MA, Piertney SB (2014) Fine-scale population epigenetic structure in relation to gastro-intestinal parasite load in red grouse (Lagopus lagopus scotica). Molecular Ecology, 23, 4256-4273.

Wenzel MA, Piertney SB (2015) Digging for gold nuggets: uncovering novel candidate genes for variation in gastrointestinal nematode burden in a wild bird species. Journal of Evolutionary Biology, 28, 807-825.

Wenzel MA, Webster LM, Blanco G et al. (2012) Pronounced genetic structure and low genetic diversity in European red-billed chough (Pyrrhocorax pyrrhocorax) populations. Conservation Genetics, 13, 1213-1230.

Wenzel MA, Webster LM, Paterson S, Mougeot F, Martínez-Padilla J, Piertney SB (2013) A transcriptomic investigation of handicap models in sexual selection. Behavioral Ecology and Sociobiology, 67, 221-234.

Wilson GR (1983) The prevalence of caecal threadworms (Trichostrongylus tenuis) in red grouse (Lagopus lagopus scoticus). Oecologia, 58, 265-268.

Yeaman S, Whitlock MC (2011) The genetic architecture of adaptation under migrationselection balance. Evolution, 65, 1897-1911.

Zueva KJ, Lumme J, Veselov AE, Kent MP, Lien S, Primmer CR (2014) Footprints of directional selection in wild Atlantic salmon populations: evidence for parasite-driven evolution? PLoS ONE, 9, e91672.

This article is protected by copyright. All rights reserved. 